\title{
Use of Mobile Technologies in Tourism: Natural Health Resorts Study
}

\author{
Boštjan Brumen* \\ Peter Planinc \\ Tomi Špindler \\ Mitja Gorenak \\ Tanja Lešnik Štuhec \\ Faculty of Tourism, University of Maribor, \\ Cesta prvih borcev 36, Si-825o Brežice, Slovenia \\ Corresponding Author
}

DOI: https://doi.org/10.36941/mjss-2020-0o36

Abstract

Mobile technologies have drastically changed the way people do everyday activities. Tasks previously reserved for desktop environments have moved to mobile devices, and nowadays, half of the internet traffic is stemming from mobile devices. The tourism industry is no exempt from the shift from desktop to mobile. In our research, we check to what extent natural health resorts have adapted and integrated mobile solutions to their websites. We collected data about the friendliness of selected websites using automated online tools and carried out a heuristic evaluation. The results were statistically analyzed and compared. Only roughly half of natural health resorts have optimized their websites for mobile devices. There are no statistically significant differences when comparing purely technical aspects. However, an in-depth heuristic evaluation has shown that some web sites are significantly more mobile-friendly than others and offer better technical conditions for enhanced user experience. Our study is the first technical and contentual evaluation of website mobile devices' friendliness in the natural health resort sector. It warns management, their marketing consultants, and web site developers about the opportunities they are missing by not supporting mobile users sufficiently. Further, it outlines deficiencies and provides suggestions and instructions for optimizing websites to enhance user-friendliness on mobile devices.

Keywords: mobile technology, mobile device, mobile Internet, health tourism, spa, natural health resort, web page, evaluation, heuristics

\section{Introduction}

Mobile phones have become a part of our everyday life and a potent multifunctional tool used in the past for voice and limited text communication only. Today's smart mobile phones have become small computers; therefore, in addition to basic telephony and text messaging, they enable essential interaction with the outside world via the Internet. Thus, reading e-mail, checking the news on social networks, shopping, and other previously "desktop" activities have become a central function of a mobile phone... wherever and whenever a mobile or wireless internet signal is available. These 
technologies now appear as physical and cognitive prostheses that give meaning and continuity to our actions, radically redefining time, space, and socio-economic balances (Capogna, Figus, \& Mustica, 2018).

The data support the fact that mobile technologies have changed our habits and behaviors. In 2019, mobile internet traffic surpassed $50 \%$ of total web traffic (Clement, 2019). This information is of crucial importance for the success of the tourism industry, which needs to adapt globally to social changes as a consequence of the increased usage of mobile devices. Changes in access to a critical promotional channel such as the World Wide Web, the ability to use mobile technologies, and consequently new innovative solutions that these technologies can enable, require thorough reflection and a quick response from the tourism sector. Days of guidebooks are long gone by (Adel, 2020). A reaction in the form of activities that will adapt the content and structure of a website of a tourism service provider to the new market conditions is crucially essential to gain and sustain a competitive advantage on the market that is shifting towards using mobile technologies rapidly. Mobile phones provide continuous functional and emotional support, and in the field of tourism, the integrated use of mobile phones is enhancing tourists' experiences (Lalicic \& Weismayer, 2018).

Spa tourism, also referred to as natural health resort tourism, is having a special place within the general European tourism industry (Lebe, 2006), in Central and Eastern Europe in general (Marvel, 2002) and countries of Slovenia and Croatia in particular (Pavlic \& Portolan, 2012; Snoj \& Mumel, 2002). The results achieved by the spa hotels, in terms of occupancy and average rates, far exceed those of the spa sector or the local hotel industry in general (Marvel, 2002), mostly due to additional value-added by particular health-related services available in these hotels. The traditional guests of natural health resorts were seniors (Lebe, 2006). Interestingly, the study by Mak, Wong, and Chang (Mak, Wong, \& Chang, 2009) reveals a trend that a large proportion of the younger population with upper-middle socio-economic status is more inclined to seek a health resort experience: those that are generally more educated and hence health-conscious and are willing to spend time and money to pamper themselves. Travelers are passionate users of mobile technologies (Lalicic \& Weismayer, 2016).

The research question we answer in this work is as follows. RQ1: "How is the Slovenian and Croatian natural health resorts industry prepared for the coming changes, namely how they have adopted their web sites to be viewed on mobile devices?" As mentioned, the younger population is spending more at health resorts and, at the same time, more frequently or even predominantly uses mobile devices in all phases of the tourism experience.

The rest of the paper is organized as follows: In Section 2, we give a brief literature review on information and communication technologies (ICT) in tourism and how mobile technologies changed the promotion channels. Additionally, we list works that address the evaluation of mobile web experience and how to measure it. In Section 3, we present our method and hypotheses about the readiness of the Slovenian and Croatian natural health resort industry's web pages for mobile browsing. In Section 4, we give the results of the analyses. In section 5, we summarize lessons learned in the form of guidelines, and in Section 6, we conclude the paper with final remarks.

\section{Literature Review}

Information and communication technology plays a vital role in tourism and is essential for its actual success (Buhalis, 1998; Buhalis \& Zoge, 2007). If, in the past, tourist companies had to invest a lot of financial resources to address their potential customers, the development of the global Internet and other communication technologies changed the addressing of customers considerably. Instead of TV ads, advertisements in newspapers, catalogs, brochures and other relatively expensive ways of promotion, in the last years, a World Wide Web has been established in its entirety, enabling customers to verify the desired offer from anywhere, without much effort, when they want and from the sources they trust. Thus, the World Wide Web has radically changed the relations between providers and consumers by providing many new ways of connecting, facilitating the availability of 
desired or necessary information, and changing the way marketing activities work, since the (global) competitiveness has significantly increased among the providers. Poon (Poon, 2003) recognized the so-called "new tourism" in the 1990 and defined it as a tourism of the future, which is very flexible, segmented, and offers an authentic tourist experience. It is essential, however, that ICT drives organizational and marketing power. He emphasizes that new information technologies will support not only individual segments within tourism, but the system as a whole, and will lead to significant competitive advantages, as future innovations in the information industry will enable them to approach potential customers. Later Buhalis (Buhalis, 2003) wrote about the so-called e-tourism that links business, information and communication technology, and tourism. He emphasized that etourism will carry out a "revolution" of all business processes and relations of tourist organizations with its stakeholders at a strategic level, while at the tactical level, as an "e-business", it will maximize the efficiency of tourist organizations. ICT is defined as "a set of electronic tools" that facilitate operational and strategic work in the organization, thereby enabling the management of information, functions, and procedures. These tools also enable interactive communication with stakeholders so that organizations can achieve their vision and goals (Buhalis, 2003). Mobile devices have brought highly relevant innovations in the e-Tourism field (Cantoni \& Saldaña, 2016).

Bethapudi (Bethapudi, 2013) stated that ICT had changed the tourism sector globally. ICT has become the leading force for moving and changing the structure of the tourism industry and has built the basis for the development of a whole range of new opportunities and dangers. It has increased the power of consumers by making it easier to recognize, adapt, and purchase the product or service. ICT drives globalization within the sector as it provides tools for the development, management, and distribution of supply worldwide. Thus, ICT represents a vital role in the competitiveness of tourism organizations. ICT has become a critical success factor in organizational competitiveness. Improved ICT capabilities, combined with reduced equipment size and cost savings, lead to improved reliability, compatibility, interconnection, and reduced costs.

COMCEC, in its research report (COMCEC, 2015), at the same time, emphasizes that in the past, tourist brands perceived high costs as a significant barrier to reaching tourists. Marketing campaigns were heavily focused on traditional press, television, radio, and billboards, and travel and tourism agencies served as "gatekeepers" for tourism brands or organizations that attempted to reach a particular market. With the development of the ICT, a new era of marketing of tourism started, which offered an alternative to tourist companies and destinations of all sizes, and now, with much fewer obstacles, they can reach their potential consumers more efficiently. Not only locally or regionally, but indeed globally. With proper use, new forms of tourism marketing can be a very costeffective and not only supplementing traditional means of reaching global target markets, but also replacing them. At the same time, they emphasize that the spreading of promotional channels to digital marketing is an increasingly demanding ecosystem, which in the beginning introduces barriers to small and medium-sized tourism companies. As the scope and accessibility of information are nowadays exponentially increasing, tourism service providers must use new methods rationally and wisely, so that they can be globally recognized. Besides, it is essential to develop effective and up-todate communications, as the rapidly evolving ICT field enables fast and consistent access to the global information network. The crucial task of these companies is, therefore, to adapt their business models so that they can better integrate information flows and continually improve their technology. New platforms and technologies require a lot of expertise, which is quite different from traditional marketing experience. All this can become a significant burden for small and medium-sized enterprises that want to enter the tourism segment market, especially if they do not have enough capital or access to expertise (COMCEC, 2015).

Not only ICT per se but mobile technologies, in particular, have a significant impact on all five phases of tourist experience (Aho Seppo, 2001) and are changing them (Brown \& Chalmers, 2003). The changes put many challenges in front of the tourist industry as service providers. Their response to the outlined challenges will reflect on their competitiveness or the ability to be recognized in the world of global competition. Ciaramitaro (Ciaramitaro, 2012) states that mobile technologies have 
become the dominant mode or medium of communication in the world, defined as a combination of various technologies, devices, and applications that mutually provide a powerful communication tool. The reach and functionality of mobile devices depend on the basic network infrastructure and the capabilities of mobile devices. However, the greatest potential and richness of mobile technologies are in a variety of applications running on mobile devices. Mobile technology is shaping the present, and according to the trends, also the future (Clement, 2019; Pencarelli, 2019), It is difficult for local people to enthusiastically accept and support tourism without receiving economic benefits (Kolawole, 2019), and mobile technologies can help create the links.

Growth and predictions about the use of smart mobile phones, other mobile devices, and the mobile web have essential implications for owners or operators of tourist companies. They need to be aware of the need to optimize and customize their websites so that they are easy to use, responsive, and offer a user-friendly experience (Zhang, 2007). They must take into account the fact that more and more smart mobile phone users use them for research, planning, sharing experiences, reporting responses, and purchasing tourist services. Regardless of how the visitors access the website (e.g., a fixed computer, laptop, tablet, smartphone, or smart TV), they must always aim to provide the same high-quality user experience. If a user needs to tap and zoom in on a web page because the text is too small or to search for the correct finger position in order to be able to press the desired button or link, it is highly likely that she will quickly leave the site - and not purchase the service. At the same time, the visitor will likely associate her negative feelings of uncomfortable user experience with a brand or a company that offers services on this site. Moreover, potential customers may be lost only at the expense of a negative mobile experience. Given the fact that more and more people are using mobile devices to browse the web, optimizations of the website to improve mobile experiences have become necessary.

Since 2015 this task had become even more critical, as Google had decided to lower position in rankings of search results for pages that are not suitable for mobile devices when a search was initiated from such a device. Starting in July 2019, google implemented the mobile-first indexing when evaluating the relevance of a page to a user's query. This means that it first uses the mobile version of the content for indexing and ranking, as opposed to the previous practice when the index used the desktop version of page content. Since the majority of users now access Google Search with a mobile device, Googlebot primarily crawls and indexes pages with the smartphone agent going forward (Google, 2019).

Mobile apps in tourism have attracted quite a lot of interest in the research community, see, e.g. (Douglas, Lubbe, \& van Rooyen, 2018; Gibbs, Gretzel, \& Saltzman, 2016; Kamboj \& Gupta, 2020; Ribeiro, Silva, Barbosa, Silva, \& Metrôlho, 2018; Rodríguez-Torrico, Prodanova, San-Martín, \& Jimenez, 2019; Tarantino, De Falco, \& Scafuri, 2019). Unfortunately, not so much research was done on mobile web pages. In the following subsections, we give an overview of research on mobilefriendly web pages in tourism.

\subsection{Mobile Web Pages}

Organizations must first understand and familiarize themselves with the types of websites before thinking about optimizing their website in order to make them mobile-friendly. In principle, there are three types of websites: adaptive, mobile (separated or for mobile devices only), and responsive (Xiao, Tao, \& Li, 2008).

An adaptive (dynamic) site generates different HTML for a page based on the user's device, regardless of screen size. A mobile site is developed specifically for a mobile device (typically with a custom "m" extension, e.g., m.example.com). A responsive web site is developed in a technique that detects the type or size of a device used by the client and then dynamically adjusts the layout of the page according to the size of the screen. The website, regardless of the device on which it is displayed, uses the same HTML and the same Uniform Resource Locator (URL), and its appearance responds according to the size of the screen. Responsive design is a recommended development 
technique to display consistent content. Search engines find and index such sites easily, and visitors can easily access such content.

Adaptive sites require additional work and maintenance, mainly to let web crawlers (robots, spiders) know there is also a mobile version available. Mobile sites have a divert issue, where a precise redirection on each subpage must be made between the stationary website and the mobile web site; automatic indexing is also more difficult. Additionally, any content that is added or changed on a classic web needs to be redesigned on a mobile website, which leads to duplicate work.

Google best describes the principal elements and characteristics of a mobile-friendly website in its research study (Google, 2014). Based on the survey, 25 principles were put together in 5 categories, which should be considered by each mobile-friendly website. They find that most mobile users expect they will get what they need simply, immediately (under 2,5 seconds), and under their conditions. An excellent usability study about the differences between adaptive and responsive DMOs' websites is by Growth and Haslwanter (Groth \& Haslwanter, 2016).

\subsection{Evaluations of mobile websites in the tourism}

The websites in tourism, intended for access with a mobile device, are not so much different from the designs, technical, and other features of other websites. However, specific characteristics in this segment are particularly important and should be defined in more detail in this paper. Most of these characteristics relate to the findings and trends identified in the previous subsections and have a particularly strong impact on the implementation of tourism promotion. Tourism is becoming a highly personalized activity; therefore, tourist organizations have an excellent opportunity to use big data to learn about travel habits and needs of potential guests, and then offer customized services with an appropriate online shopping experience; mobility does not positively influence purchase intentions per se (Chuang, 2019), but only if the content is useful and adjusted to the context (Rodríguez-Torrico et al., 2019). Such targeting and personalization are becoming important digital priorities, which, of course, require web page adjustments. Here, new technological possibilities, such as good video content (Reino \& Hay, 2016; Turnšek \& Janecek, 2019), 360-degree panoramas (Kelling, Väätäjä, \& Kauhanen, 2017), virtual tour of a destination or a hotel (Cho, Wang, \& Fesenmaier, 2002), can drastically contribute to successful sales. Of course, they must first be implemented successfully on mobile-friendly websites.

While webpage evaluation using traditional browsers from personal computer environmentsdesktop or laptop-has been widely studied also in the tourism area, see, e.g. (Benevolo \& Spinelli, 2019; Daries, Cristobal-Fransi, Ferrer-Rosell, \& Marine-Roig, 2018; de Rosa, Bocci, \& Dryjanska, 2019; Doolin, Burgess, \& Cooper, 2002; Fernández-Cavia, Rovira, Díaz-Luque, \& Cavaller, 2014; Foris, Tecau, Hartescu, \& Foris, 2019; Jiménez-Barreto \& Campo-Martínez, 2018; Law, Qi, \& Buhalis, 2010; LunaNevarez \& Hyman, 2012; Mandal, Roy, \& Raju, 2017; Martínez-Sala, Monserrat-Gauchi, \& AlemanyMartínez, 2020; Morais, Cunha, \& Gomes, 2019; Morrison, Taylor, \& Douglas, 2004; Stienmetz, Levy, \& Boo, 2013; Yeung \& Law, 2004), mobile browsing from smartphones, touch phones, and tablets present new usability challenges (Inostroza, Rusu, Roncagliolo, Jimenez, \& Rusu, 2012); and only very few recent studies deal with tourism-related sites, e.g. (Groth \& Haslwanter, 2016; Leung \& Dickinger, 2019).

The basis for our research and the preparation of a guided list for the evaluation of mobile web pages was the research article entitled "Heuristic Evaluation on Mobile Interfaces: A New Checklist" (Yáñez Gómez, Cascado Caballero, \& Sevillano, 2014). The authors of the study found that the existing managed lists are incomplete and inadequate for testing websites that users access with mobile devices, so they modified already existing categories of managed lists, while also creating and adding 72 new heuristics that relate to the evaluation of mobile web sites pages so that they can offer the same quality user experience to mobile users as to those using a desktop computer. The authors proposed the use of a heuristic method in mobile web site testing. A heuristic evaluation is a method to help us find problems with the usability or design of the user interface (Nielsen \& Molich, 1990). 
Usually, this evaluation is included as part of a recurring interface design process. A heuristic evaluation includes a reviewer or a small set of reviewers who examine a particular interface and assess its compliance with recognized principles of use (heuristics).

In our research on the friendliness of Slovenian and Croatian natural health resorts' websites, we have used a guided list of 72 heuristics from (Yáñez Gómez et al., 2014) as recognized principles of usability, which every web page that will appear on a mobile interface should contain.

\section{Methods}

\subsection{Hypothesis}

As part of our research, we will determine whether the data obtained from "mobile-friendliness" tests support the following null hypothesis:

$\mathrm{H}_{\mathrm{o}}$ : there are no differences between the analyzed web pages of Croatian and Slovenian natural health resorts in their friendliness to mobile devices.

\subsection{Population and source of data}

Our research population is all Slovenian and Croatian verified natural health resorts and their corresponding web pages. Natural health resorts in Slovenia and Croatia receive a "verified" status by the government if natural resources (e.g., thermal water) used in treatments have a scientifically proven healing effect based on respective laws (in Slovenia: Natural Remedies and Natural Health Resorts Act; in Croatia: Health Care Act).

\subsection{Data acquisition and technical analysis}

Two technical analyses and heuristic evaluations were carried out on 29 web pages. We first performed a technical analysis for the mentioned websites with Google's Mobile-Friendly Test webbased tool, which is located at https://search.google.com/test/mobile-friendly. The web interface allows entering the URL of a web page to be analyzed. It provides the following information:

- The website is/is not mobile-friendly.

- Indication of the reasons why the website is not mobile-friendly.

- Other information on the performance of the test and information on the necessary optimization.

We recorded data on whether the website "is" or "is not" friendly to mobile devices. In case that the web interface detected that the website is not user-friendly for mobile devices, we listed the number and descriptions of detected errors.

The second test of our technical analysis was carried out with the Mobile SEO web tool, which is located at https://varvy.com/mobile. The web interface allows entering the URL of a web page that needs to be analyzed. It provides the following information:

- friendliness for mobile devices (max. 100 points).

- speed of the website on the mobile device (max. 100 points).

- information about the availability of information for Google search crawlers.

- a number of redirects made on the website.

- other detailed incorrect configurations or errors detected, affecting the use on a mobile device.

Besides, the site provides useful information about website optimization to improve user experience using a mobile device and offers guidance on the elimination of identified shortcomings.

We recorded the number of points scored for the user-friendliness of the mobile device, the number of points scored for the speed of the website on a mobile device, as well as the number and description of the detected errors according to the criteria of the friendliness for a mobile device and 
Google search crawler access. This has a significant impact on the proper positioning of the site on the Google search engine.

The third testing of web pages was done using the heuristic evaluation method by using heuristics developed by (Yáñez Gómez et al., 2014). During the evaluation, we scored the answers. Each positively evaluated heuristic was evaluated by 1 point and with o points negative and not evaluated heuristic. Each analyzed web site could score a maximum of 72 points. The results are shown in \% of points achieved, and in the number of unrated heuristics (unanswered questions), because it gives information that certain websites are content- and functionally wise very modest.

We first got thoroughly acquainted with each web site. We checked their functionalities on a desktop HP Elite 7100 computer (Windows 10 Professional, 32 bit, Intel ${ }^{\oplus}$ Core $^{\text {TM }}$ i5 650, RAM 4 GB, Internet browser Firefox version 48.o.2) as well as on a mobile device. The stationary desktop computer was connected to the network via a wired network connection by the provider "Si.mobil," with a transfer speed of $20 \mathrm{Mbit} / \mathrm{s}$. The mobile device used was a Samsung Galaxy SIII device (GTI9305, Quad-core 1.4 GHz Cortex-A9, RAM 2 GB RAM, Android 4.4.4 version, Chrome version 52.0.2743.98) and through mobile data transmission using Si.mobil's $4 \mathrm{G}$ network, with the speed of up to $20 \mathrm{Mbit} / \mathrm{s}$. Network speeds were measured using the "Network speed test" tool and "Speedtest by Ookla" app for desktop and mobile environments, respectively.

\subsection{Data analysis}

We processed the acquired data in Microsoft Excel 2013 and IBM SPSS v.23. The obtained data from the technical analyses were manually entered (transcribed from the web interfaces) into an Excel table. We also entered individual responses obtained from the heuristic evaluation. For simple data analysis, we used Excel's built-in functions, such as counting individual responses, calculating percentages, calculating mean values, and graphical representations. IBM SPSS version 23 was used for statistical analyses. The threshold for rejecting a null hypothesis was set at $\alpha=0.05$.

\section{Results}

Initially, we point our that certain websites of Slovenian resorts are using the same platform. The unification of the websites is based on the ownership of the individual resorts/companies. Uniform websites are shared by resorts owned by pharmaceutical company Krka, i.e., Terme Dolenjske Toplice, Terme Šmarješke Toplice, and Talas Strunjan. Similarly, resorts Terme Lendava, Terme 3000 Moravske Toplice, Terme Ptuj, and Zdravilišče Radenci, which are owned by Sava Hotels \& Resorts, also have a shared web platform. These resorts do have at first glance different websites, but sites are managed on a single platform and with unified functionality. In Croatia, the health resorts are not ownership-linked as in Slovenia. They are still in public (government) ownership; therefore, they also do not have or share a common platform.

\subsection{Descriptive statistics}

Firstly, we measured the mobile-friendliness of Slovenian and Croatian natural health resorts' websites using the online Google's Mobile-Friendly Test application. Based on this test, out of 14 analyzed URLs of Slovenian resorts, nine websites are mobile-friendly, and five websites are not optimized for use on a mobile device (Figure 1). As a reason that the website is not suitable for use on a mobile device, the tool gives the following four errors: the text is difficult to read because the font is too small; the content is wider than the screen; the links are too close together; no mobile area visible.

Out of 15 Croatian resorts' websites, six were identified as mobile-friendly. At the same time, for the other nine sites, the tool detected irregularities, which relate to small text size, and inadequately determined display size of a device or the links are too close together; therefore, they were identified 
as mobile not friendly.

Mobile Friendly Websites, Slovenia

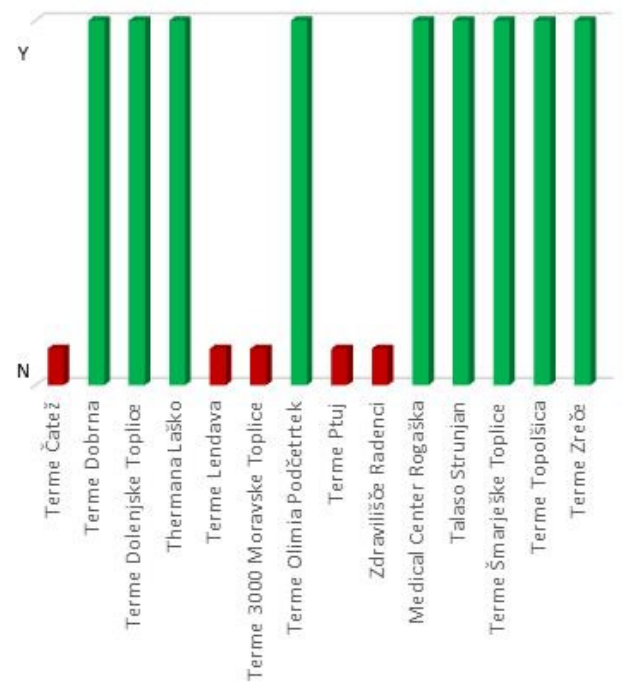

Mobile Friendly Websites, Croatia

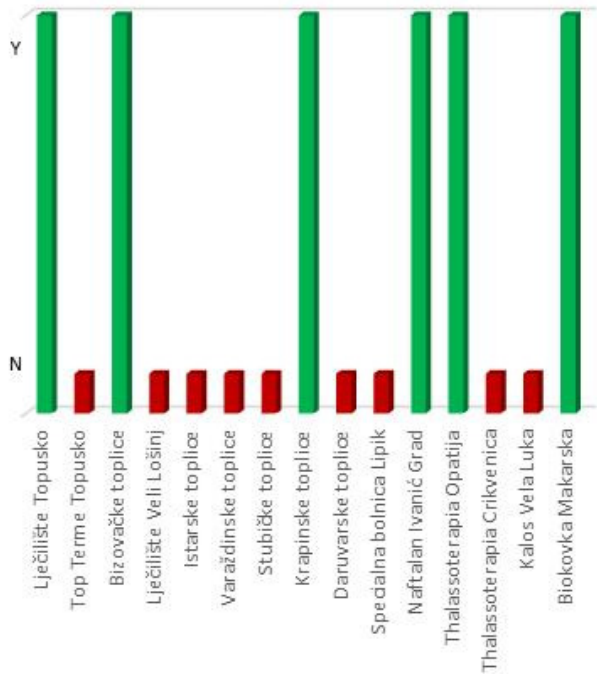

Figure 1: Test \#1: mobile-friendliness of resorts' web pages, Slovenia and Croatia

The second test of our research was done with the Mobile SEO tool. This tool provided information on the number of points achieved (out of possible 100) for the two categories: friendliness of a website to a mobile device and the responsive speed of a website on a mobile device. Based on the tests carried out on all websites, we find that 90 or more points mean the website is correctly optimized for mobile devices. Lack of full responsiveness (10o points) is detected on all analyzed web pages, which is probably because the websites are made universally (both for desktop and mobile use), regardless of whether they are responsive or dynamic sites. When creating either a responsive or a dynamic web site, it is always necessary to compromise between functionality, content width, and speed or responsiveness on a mobile device, and the latter is usually the victim of such a solution.

The results of the analysis using this test within Slovenian natural health resorts are not much different from the results of the first test. Again, out of 14 the analyzed web sites, 9 met these criteria, and five did not. This means that five resorts have an inadequate online solution, namely Terme Čatež and four other health resorts under the Sava Hotels\&Resorts chain. Otherwise, the average score is 86 points and 56 points, for "mobile-friendliness" and "speed on mobile device" criterion, respectively (Figure 2 ). The test also checked the proper settings for the Googlebot crawler. It has been established that all websites of Slovenian resorts are adequately optimized from this point of view.

However, this test strictly checked the suitability of links on pages - the spatial distances between individual links. Warnings about this inconsistency were found for some websites that are generally recognized as mobile-friendly (even for web pages that scored 98 or 99 points). 


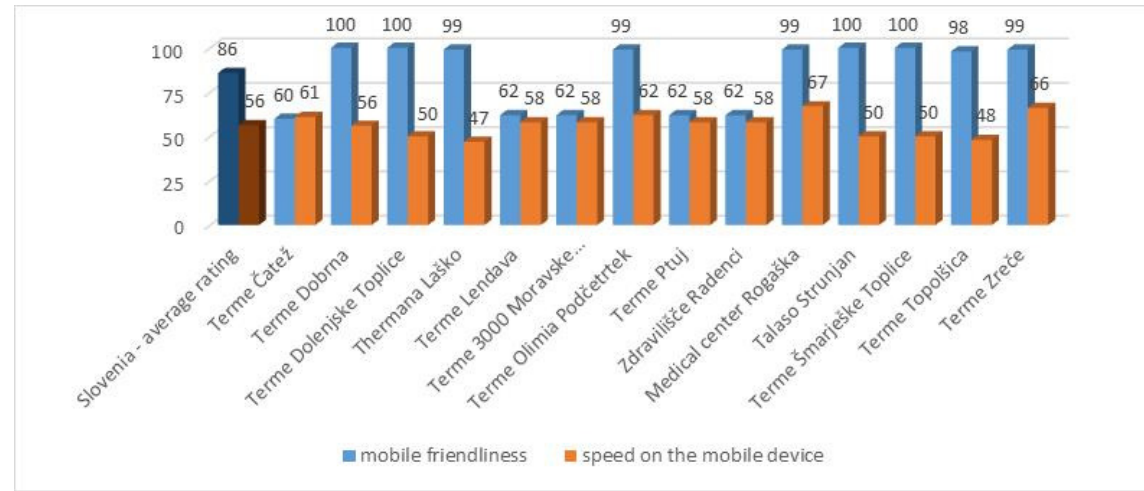

Figure 2: Test \#2: web site scores of Slovenian natural health resorts using Mobile SEO

The second test, using the Mobile SEO tool, on Croatian natural health resorts' sites reveals very similar data to the first test. However, there are additional speed-related problems. It has been found that out of the 15 analyzed websites, only two websites reached at least 90 points for friendliness and a minimum of 40 points for speed. Thalassotherapia Opatija's website was not analyzed with this tool at all because it has extremely poor responsiveness or other incorrect configurations that make it impossible to run the test. Therefore, this website is marked as not mobile friendly and not tested. The averages for Croatian sites are 79 and 50 points for "mobile-friendliness" and "speed on the mobile device," respectively (Figure 3).

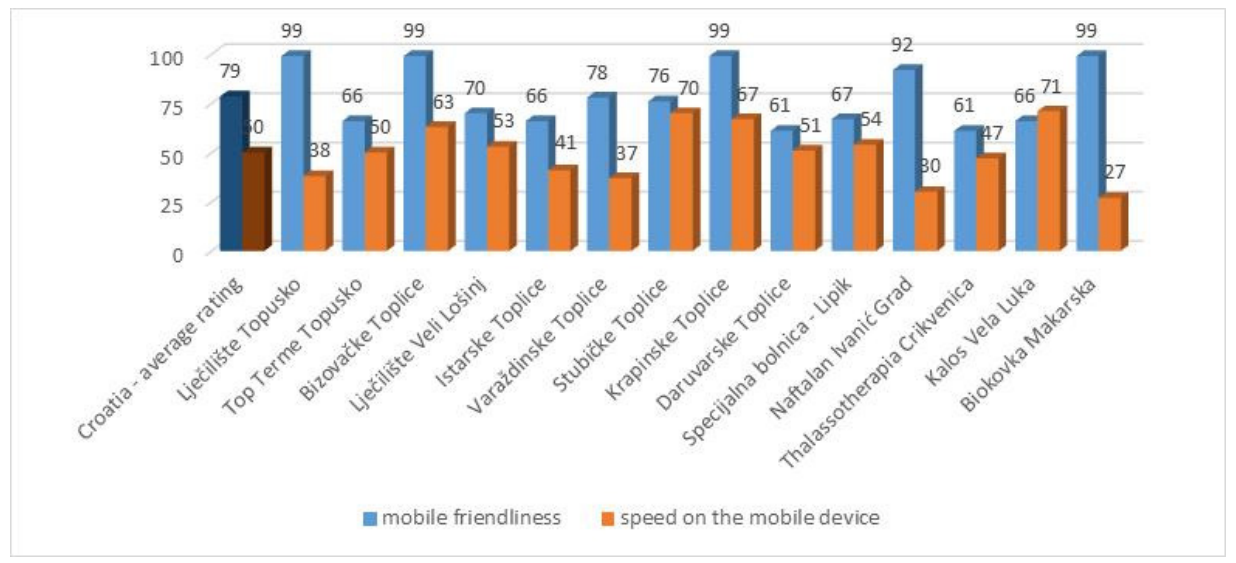

Figure 3: Test \#2: web site scores of Croatian natural health resorts using Mobile SEO

Additionally, three Croatian websites were not correctly optimized for the accessibility of the Googlebot search crawler. Four websites that the tool recognized as mobile-friendly had nonconformity due to the small distance between individual links.

The third test was a heuristic evaluation of web pages based on the managed list of 72 heuristics, as mentioned above. The result of the assessment is shown as a ratio between positively assessed heuristics and all possible answers. Additionally, we provide information on the number of missed heuristics, because this information indirectly tells that certain websites do not have some essential functionalities, such as an appropriate or operative search engine, a reservation system, input forms, video content, etc. 
In Figure 4, data on the heuristic evaluation of Slovenian web pages is presented.

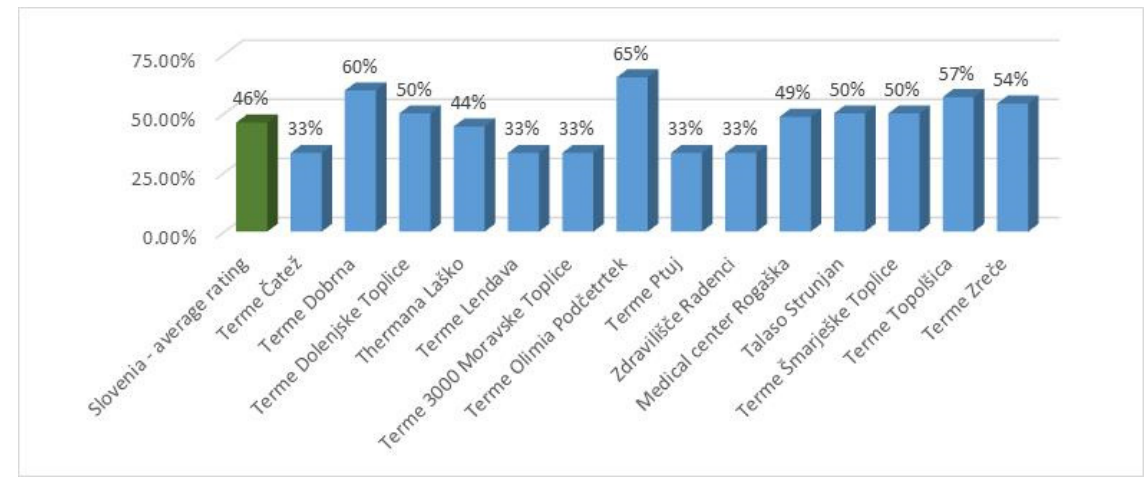

Figure 4: Test \#3, heuristic evaluation, Slovenian natural health resorts

Based on the data, the most mobile user-friendly and personalized websites are those by Terme Olimia Podčetrtek, Terme Dobrna, Term Topolščica, and Terme Zreče. Also suitable are sites under the brand name Terme Krka (Šmarješke \& Dolenjske Toplice, Talaso Strunjan), the websites of the Medical Center Rogaška and Thermana Laško. These are the same sites already identified as mobilefriendly by the other two tests, so we can confirm that the data of all three tests are very harmonized. Based on this test, 9 Slovenian natural health resorts have a satisfactory online mobile-friendly solution, and the other five do not. The average heuristic is $46 \%$, with an average of untested 14,3 heuristic questions.

We estimate that the approximate threshold for a website that could be declared as a mobilefriendly is at least $40 \%$. After analyzing the heuristic evaluation responses, we find that out of the 14 Slovenian health resorts' websites evaluated nine websites obtained a score of over $40 \%$.

The heuristic evaluation of Croatian natural health resorts data indicates somehow worse results. Only four websites reached the threshold of $40 \%$, namely Krapinske Toplice, Stubičke Toplice, Naftalan Spa, Ivanić Grad, and Biokovka Makarska (Figure 5).

Other web sites could be classified as incompletely adjusted for mobile devices. However, there are websites of Bizovačke Toplice, Toposko Spa, and Thalassotherapia Opatija health resorts, for which we cannot say they are mobile-friendly. For Croatian resorts websites, the average ratio of positively assessed heuristics is $36,5 \%$.

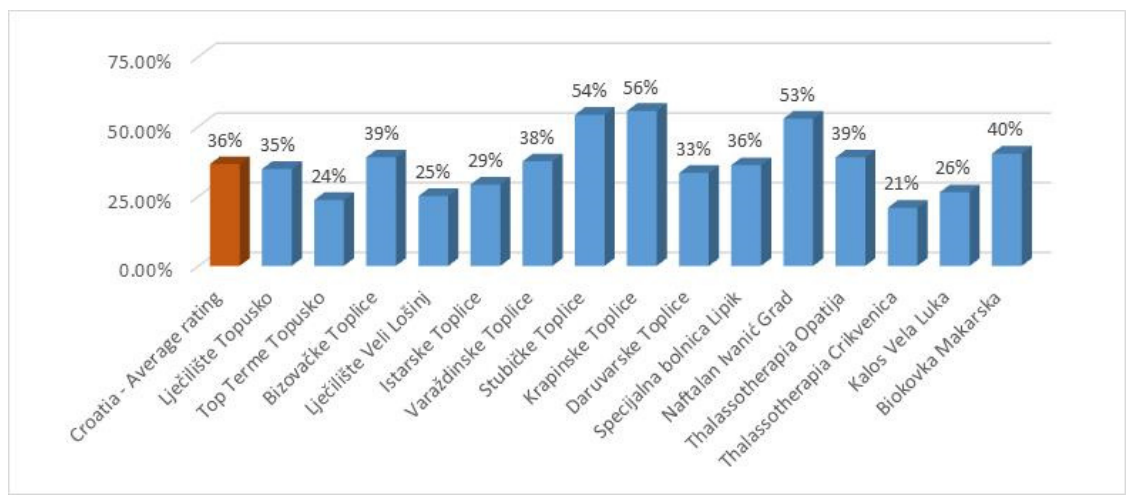

Figure 5: Test \#3, heuristic evaluation, Croatian natural health resorts 


\subsection{Analysis of differences between Slovenian and Croatian websites}

In the previous section, we found that the results for the Slovenian websites differ from the results for Croatia and that, at first glance, Slovenian websites are better suited to mobile devices. In this section, we will use statistical analyses to determine whether the differences are a result of coincidences or whether they are statistically significant.

Firstly, we are interested if there are differences in mobile readiness (yes/no), as reported by the Google Mobile Friendliness tool (see Figure 1). A chi-square test for independence is used to find out whether any statistically significant association between country and mobile-friendliness exists; that is, whether both country resorts' sites are equally mobile-friendly. The results of the test are presented in Table 1.

Table 1: Results of the Chi-Square test

\begin{tabular}{|c|c|c|c|c|c|}
\hline & Value & & Asymptotic significance (2-sided) & Exact Sig. (2-sided) & Exact Sig. (1-sided) \\
\hline Pearson Chi-Square & $1,710^{\mathrm{a}}$ & 1 & 0,191 & & \\
\hline Continuity Correction & o,876 & 1 & 0,349 & & \\
\hline Likelihood Ratio & 1,729 & 1 & 0,189 & & \\
\hline Fisher's Exact Test & & & & 0,272 & 0,175 \\
\hline $\mathrm{N}$ of Valid Cases & 29 & & & & \\
\hline
\end{tabular}

a. o cells $(o, 0 \%)$ have expected count less than 5 . The minimum expected count is 6,76 .

With $\mathrm{P}=0,191$, there are no statistically significant differences in mobile-friendliness between the two countries resorts' sites.

Secondly, we are interested in the differences between the average values listed in Table 2.

Table 2: Average values for different mobility friendliness tests

\begin{tabular}{|c|c|c|c|}
\hline Test & Parameter & Group & Average \\
\hline \multirow{2}{*}{ \#1, Google Mobile-Friendly } & \multirow{2}{*}{ Number of errors } & Slovenia & 1,43 \\
\hline & & Croatia & 1,93 \\
\hline \multirow{4}{*}{ \#2, Mobile SEO } & \multirow{2}{*}{ Mobile-friendliness } & Slovenia & 85,86 \\
\hline & & Croatia & $73,72\left(78,50^{1}\right)$ \\
\hline & \multirow{2}{*}{ Speed } & Slovenia & 55,38 \\
\hline & & Croatia & $46,60\left(49,93^{1}\right)$ \\
\hline \multirow{4}{*}{ \#3, Heuristics } & \multirow{2}{*}{ Ratio } & Slovenia & 46,13 \\
\hline & & Croatia & 36,48 \\
\hline & \multirow{2}{*}{ Unanswered questions } & Slovenia & 14,29 \\
\hline & & Croatia & 22,13 \\
\hline
\end{tabular}

'Thalassoterapia Opatija removed because the tool was unable to calculate the values; zero taken otherwise

We have two groups, Slovenian and Croatian sites, for which we claim they are mutually independent since there are no known relations among them, such as, e.g., ownership or platform sharing. With two independent groups and numerical values, we can use a parametric t-test or non-parametric Wilcoxon test. The normal distribution test (Table 3) determines which one of these to use. 
Table 3: Normality distribution test

\begin{tabular}{|c|c|c|c|c|c|}
\hline \multirow{2}{*}{ Test } & \multirow{2}{*}{ Parameter } & \multirow{2}{*}{ Group } & \multicolumn{3}{|c|}{ Shapiro-Wilk } \\
\hline & & & Statistic & $\mathrm{df}$ & Sig. \\
\hline \multirow{2}{*}{ \#1, Google Mobile-Friendly } & \multirow{2}{*}{ Number of errors } & Slovenia & 0,782 & 14 & 0,000 \\
\hline & & Croatia & 0,616 & 15 & 0,002 \\
\hline \multirow{4}{*}{ \#2, Mobile SEO } & \multirow{2}{*}{ Mobile-friendliness } & Slovenia & 0,647 & 14 & 0,000 \\
\hline & & Croatia & 0,796 & 15 & 0,003 \\
\hline & \multirow{2}{*}{ Speed } & Slovenia & 0,926 & 14 & 0,264 \\
\hline & & Croatia & 0,936 & 15 & 0,332 \\
\hline \multirow{4}{*}{ \#3, Heuristics } & \multirow{2}{*}{ Ratio } & Slovenia & 0,880 & 14 & 0,059 \\
\hline & & Croatia & 0,926 & 15 & 0,239 \\
\hline & \multirow{2}{*}{ Unanswered questions } & Slovenia & 0,914 & 14 & 0,180 \\
\hline & & Croatia & 0,896 & 15 & 0,083 \\
\hline
\end{tabular}

Because of a small number of measurements in each group ( $n=14$ / Slovenia; $n=15$ / Croatia), we use the Shapiro-Wilk test. The results show that t-test should be used for test \#3, and parameter "speed" for test \#2, and non-parametric Wilcox test for the test \#1 and parameter "mobile-friendliness" for test \#2. The t-test results are shown in Table 4.

Table 4: T-test of independent samples

\begin{tabular}{|c|c|c|c|c|c|c|c|c|c|c|}
\hline & & \multicolumn{2}{|c|}{$\begin{array}{c}\text { Levene's Test for } \\
\text { Equality of } \\
\text { Variances }\end{array}$} & \multicolumn{7}{|c|}{ t-test for Equality of Means } \\
\hline & & \multirow[t]{2}{*}{$\mathrm{F}$} & \multirow[t]{2}{*}{ Sig. } & \multirow[t]{2}{*}{$\mathrm{t}$} & \multirow[t]{2}{*}{ df } & \multirow{2}{*}{$\begin{array}{l}\text { Sig. (2- } \\
\text { tailed) }\end{array}$} & \multirow{2}{*}{$\begin{array}{c}\text { Mean } \\
\text { Difference }\end{array}$} & \multirow{2}{*}{$\begin{array}{l}\text { Std. Error } \\
\text { Difference }\end{array}$} & \multicolumn{2}{|c|}{$\begin{array}{c}95 \% \text { CI of the } \\
\text { Difference }\end{array}$} \\
\hline & & & & & & & & & Lower & Upper \\
\hline \multirow{2}{*}{$\begin{array}{l}\text { Mobile SEO } \\
\text { Speed }\end{array}$} & $\begin{array}{l}\text { Equal variances } \\
\text { assumed }\end{array}$ & 7,357 & o,o11 & 1,834 & 27 & 0,078 & 9,757 & 5,320 & $-1,158$ & 20,672 \\
\hline & $\begin{array}{l}\text { Equal variances } \\
\text { not assumed }\end{array}$ & & & 1,887 & 17,482 & 0,076 & 9,757 & 5,172 & $-1,132$ & 20,646 \\
\hline \multirow{2}{*}{$\begin{array}{l}\text { Heuristics } \\
\text { Ratio }\end{array}$} & $\begin{array}{l}\text { Equal variances } \\
\text { assumed }\end{array}$ & 0,204 & 0,655 & 2,353 & 27 & 0,026 & 9,64729 & 4,09995 & 1,23488 & 18,05969 \\
\hline & $\begin{array}{l}\text { Equal variances } \\
\text { not assumed }\end{array}$ & & & 2,352 & 26,802 & 0,026 & 9,64729 & 4,10206 & 1,22764 & 18,06693 \\
\hline \multirow{2}{*}{$\begin{array}{l}\text { Heuristics } \\
\text { Unanswered } \\
\text { Questions }\end{array}$} & $\begin{array}{l}\text { Equal variances } \\
\text { assumed }\end{array}$ & 14,407 & 0,001 & $\begin{array}{c}- \\
4,594\end{array}$ & 27 & 0,000 & $-7,848$ & 1,708 & $-11,353$ & $-4,342$ \\
\hline & $\begin{array}{l}\text { Equal variances } \\
\text { not assumed }\end{array}$ & & & $\begin{array}{c}- \\
4,709\end{array}$ & 19,231 & o,ooo & $-7,848$ & 1,667 & $-11,333$ & $-4,362$ \\
\hline
\end{tabular}

Parameters of the heuristic method statistically significantly differ for the Slovenian and Croatian websites ( $\mathrm{P}=0,026$ and $\mathrm{P}<0,005$ for the parameters "ratio" and "unanswered questions," respectively). The difference between the average loading speed of Slovenian and Croatian mobile websites is statistically not relevant $(\mathrm{P}=0,076$; Levene's test dictates that equal variances cannot be assumed).

The difference between the mean values of the remaining parameters is checked by a nonparametric Wilcoxon test. The test result showed that the null hypothesis of equality of the medians ("number of errors" - Google Tool and "mobile-friendliness" - SEO Mobile tool) could not be rejected. The test statistics are $\mathrm{P}=0,272$ and $\mathrm{P}=0,143$ for "number of errors," and "Mobile SEO Friendliness," respectively, as shown in Table 5 . 
Table 5: Wilcoxon test of independent samples

\begin{tabular}{|c|c|c|c|}
\hline Null Hypothesis & Test & Sig. & Decision \\
\hline $\begin{array}{l}\text { The medians of the Number of Errors are the same } \\
1 \text { across categories of Country. }\end{array}$ & Independent-Samples Median Test & $0,272^{\mathrm{a}}$ & $\begin{array}{l}\text { Retain the null } \\
\text { hypothesis. }\end{array}$ \\
\hline $\begin{array}{l}\text { The medians of Mobile SEO Friendliness are the } \\
2 \text { same across categories of Country. }\end{array}$ & Independent-Samples Median Test & $0,143^{a}$ & $\begin{array}{l}\text { Retain the null } \\
\text { hypothesis. }\end{array}$ \\
\hline
\end{tabular}

${ }^{a}$ Exact significance is displayed for this test. Asymptotic significances are displayed. The significance level is o,o5.

The results indicate no statistically significant difference between Slovenian and Croatian websites for parameter "mobile-friendliness." However, the average value is in favor of Slovenian sites, but this could be due to a chance alone. Likewise, the number of errors detected by Google's tool does not statistically significantly differ between Slovenian and Croatian websites.

\subsection{Comparison of the results between Slovenia and Croatia}

The first test, Google's Mobile-Friendly Test, revealed that, on average, $64 \%$ of the Slovenian natural health resorts' websites were identified as mobile-friendly compared to only $40 \%$ of the Croatian ones. The average number of detected errors is 1,4 and 1,9 on the Slovenian and Croatian websites, respectively.

The second test, using the Mobile SEO web tool, yielded similar results. The average score on parameter "speed on mobile device" is 86 points for Slovenian and 79 points for Croatian sites, and on the parameter "mobile-friendliness," the average scores are 56 and 50, respectively. Here it is necessary to note that the measurements were performed in Slovenia and not in Croatia. Lower speeds could be attributed to a longer access time due to greater physical distance. We also checked whether sites are appropriately configured for indexing by Googlebot's crawl. All websites of Slovenian resorts are correctly configured, while four Croatian websites do not provide enough and appropriate data for Google indexing.

The third test was conducted using a heuristic evaluation method. We calculated the average of the ratios between positively assessed heuristics and all possible answers. For Slovenian websites, this average is $46 \%$, while for Croatia, it is $36 \%$.

At first glance and looking at the average values, the websites of natural health resorts in Slovenia have better results than those in Croatia, consistently across all tests. However, the statistical analyses have found no statistically significant differences in mobile-friendliness if taken as a yes/no answer among the two countries. Additionally, no significant differences were found on the number of website errors and on scores provided by the SEO tool on parameters "speed on a mobile device" and "mobile-friendliness." Hence, the differences could be due to a chance alone.

On the other hand, the results of the heuristic evaluation are statistically different on both parameters, the ratio of positively answered questions, and the number of unanswered questions. With heuristic evaluation, we made an in-depth analysis of the website content on 72 different parameters. The test reveals that Croatian natural health resorts sites are functionally and contentwise more modest than their Slovenian counterparts. In practice, it means that they are usually without a reservation system, in many cases without content search engines, input forms, multimedia content, and similar features expected nowadays in contemporary mobile pages.

The hypothesis presented in subsection 3.1 cannot, in general, be rejected. Sites from both countries are equally (not) ready to be viewed in mobile environments. However, a detailed analysis using heuristics has shown that content-wise and functionality-wise, the Slovenian sites have more to offer to a mobile user, and here a statistically significant difference exists. 


\section{Suggestions for a Mobile-Friendly Website in Natural Health Resorts Sector}

The results of the theoretical and practical part of this paper imply that natural health resorts operators in Croatia and Slovenia will have to pay more attention to the mobile segment beyond the visual optimization of the pages. This will require serious, demanding, and professional work. It is essential to create positive customer interest and a good first impression with a quality user experience on a mobile device.

Based on the literature review and trends, we recommend a responsive website, because it allows optimal flexibility, relatively fast loading of a website and, above all, unified content regardless of the device used, and even of the language used.

General guidelines for the optimization of websites in (natural health resorts) tourism industry are relying on the perceived mistakes we found during heuristic evaluation, and are as follows:

- Use navigation, which is friendly to the tips of fingers. The links and buttons should be positioned appropriately, sufficiently apart to avoid selection errors. The navigation should be grouped into categories to make it easier to select. Active areas should be visually recognizable, already visible from the shape of an element that can be taped. It should only be possible to move vertically, and the content should only be displayed in one active browser window.

- It is necessary to determine the optimum field of vision regardless of the size of the screen and type of device to use the full screen of the device. The font must be of such size that the text should be read without enlarging, the image should be fully visible without scrolling the screen.

- Use options provided only by a smart mobile device and installed dedicated applications. It should be allowed to replace the orientation of the screen, especially when viewing multimedia content. Users should have a possibility of direct dialing of contact numbers and, in particular, redirecting and sharing content through social media, with built-in functions of a smart device.

- Include features that enable users to find the information quickly, so use advanced web content search engines, enable the ability to categorize and filter the content, use multiple page numbers in case of heavier data loading (images, other multimedia content). Input fields should store previously entered content and offer templates or automated repairs. Text entries should be generally short and straightforward.

- The content should offer many photos (e.g., Instagram) and video content (e.g., YouTube).

- Only functions and contents that operate without significant interventions in the device should be used, or which do not require an upgrade of a device or installation of dedicated applications.

- Each page or subpage must be loaded under three seconds, preferably under 2,5 seconds. The caching control errors should be checked, image optimizations edited, cascading styles used, and so on. Usually, these tasks require that websites are created by experts who have extensive experience and use modern tools for creating websites.

- The user or potential customers should be offered as much interaction options as possible. Users should be permitted to evaluate their offer, enable data to be transmitted through input forms, e-mails, social media. Content should encourage users to communicate, allow them to tag, store, and share their favorite offers.

- Encourage users to register. Registered users should have a personalized offer, the default settings and data should be offered to her based on past usage.

- Users should be encouraged by a prize (e.g., in the case of registration, the user is offered a suitable discount or an additional service).

- A website should contain an advanced and transparent reservation system, and the user should use as little clicks as possible to complete a purchase. It is essential to ensure proper security of users' data and comply with applicable laws. 
- Good graphic designers and marketers should be involved in the preparation of the website. The designers should create a modern and visually pleasing web interface, choose an appropriate font, and offer content with a visual impact, while marketers should offer innovative services.

\section{Conclusions}

The development of mobile networks and innovations in mobile devices has caused incredible growth in their use. Nowadays, more than half of worldwide internet traffic is stemming from mobile devices (Clement, 2019). The devices have become a powerful personal tool, actually small computers that have changed our everyday habits of communicating, making, and sustaining personal contacts, getting information, and performing other tasks. They undoubtedly have changed the ways of the tourism industry is doing business because potential customers nowadays require instant information gratification (WTO, 1999), both location and time-wise.

Following the trend that users predominantly use mobile devices for information gratification, also for tourism purposes, the goal of this study was to check whether Slovenian and Croatian natural health resorts websites are mobile-ready and if there are any differences in mobility friendliness between the two countries resorts' sites. We measured the quality of the mobile user's experience, evaluated and tested their web solutions, and identified the strengths and weaknesses that ultimately could present a significant competitive advantage.

The results are somehow worrying; almost half of the websites are not mobile-friendly. Superficial analysis using readily available online tools, such as Google's Mobile-Friendly Test and Mobile SEO, revealed that even mobile-friendly sites have some issues and could have further been optimized. The statistical analyses have shown no significant differences between Slovenian and Croatian natural health resorts' websites when evaluated by the mentioned online tools. However, an in-depth analysis using the heuristic method revealed significant differences in favor of Slovenian websites.

Based on the results of the present research, half of the providers are aware of mobile technology trends. They are respecting current principles and recommendations in the preparation of mobile websites. They have already integrated their solutions on the core websites and provide an appropriate user experience when viewing the site using a mobile device; thus, their websites are mobile-friendly. However, in order for the user experience to become even better, a few more optimizations and upgrades will be needed. Additionally, they should take into account certain advantages and limitations of mobile devices, such as touch screen size, device processing power and battery capacity, camera, GPS, call functions, and connectivity with other dedicated applications ...).

It will be essential to include certain features such as advanced search engines, interactivity with users (online media, forums, input forms, gamification), and to create simple, secure, and advanced reservation systems. The latter is especially true when referring to Croatian natural health resorts' sites, which in principle, do not lag behind Slovenian sites; however, according to the heuristic analysis of data, they still have plenty of room to improve.

Given the anticipation that the incredibly rapid development of mobile technologies will continue in the future, it should be noted that website optimization is not a one-time action, but continuous and ongoing work. It requires continuous monitoring of advances in mobile technology solutions and the introduction of innovative approaches and services.

\section{Acknowledgments}

The author acknowledges the financial support from the Slovenian Research Agency (research core funding No. P2-0057, project funding No. V5-1725) and the University of Maribor (http://www.um.si, core funding). No grants were received from other institutions. 


\section{References}

Adel, M. (2020). North Africa in the Tourist Guidebooks of the 19th and Early 2oth Centuries. Mediterranean Journal of Social Sciences, 11(3). doi:https://doi.org/10.36941/mjss-2020-0030

Aho Seppo, K. (2001). Towards a general theory of touristic experiences: Modelling experience process in tourism. Tourism Review, 56(3/4), 33-37. doi:https://doi.org/10.1108/ebo58368

Benevolo, C., \& Spinelli, R. (2019). The use of websites by Mediterranean tourist ports. Journal of Hospitality and Tourism Technology, 10(2), 190-204. doi:https://doi.org/10.1108/JHTT-09-2017-0097

Bethapudi, A. (2013). The role of ICT in tourism industry. Journal of Applied Economics and Business, 1(4), 67-79.

Brown, B., \& Chalmers, M. (2003). Tourism and mobile technology. Paper presented at the ECSCW 2003, Dordrecht, Netherlands.

Buhalis, D. (1998). Strategic use of information technologies in the tourism industry. Tourism Management, 19(5), 409-421. doi:https://doi.org/10.1016/so261-5177(98)ooo38-7

Buhalis, D. (2003). eTourism: Information technology for strategic tourism management: Prentice Hall.

Buhalis, D., \& Zoge, M. (2007). The Strategic Impact of the Internet on the Tourism Industry. In M. Sigala, L. Mich, \& J. Murphy (Eds.), Information and Communication Technologies in Tourism 2007 (pp. 481-492): Springer Vienna.

Cantoni, L., \& Saldaña, M. T. L. (2016). Mobile systems for tourism. Information Technology E Tourism, 16(2), 149151. doi:https://doi.org/10.1007/s40558-016-0057-o

Capogna, S., Figus, A., \& Mustica, S. (2018). The Challenges for Digital Society: Education and E-Leadership. International Journal of Innovation and Economic Development, 4, 12-19. doi:https://doi.org/10.18775/ijied.1849-7551-7020.2015.43.2002

Cho, Y.-H., Wang, Y., \& Fesenmaier, D. R. (2002). Searching for experiences: The web-based virtual tour in tourism marketing. Journal of Travel E Tourism Marketing, 12(4), 1-17.

Chuang, C.-M. (2019). A current travel model: smart tour on mobile guide application services. Current Issues in Tourism, 1-20. doi:10.108o/13683500.2019.1631266

Ciaramitaro, B. L. (Ed.) (2012). Mobile Technology Consumption: Opportunities and Challenges. Hershey, PA, USA: IGI Global.

Clement, J. (2019). Mobile internet traffic as percentage of total web traffic in August 2019, by region. Retrieved from https:/www.statista.com/statistics/306528/share-of-mobile-internet-traffic-in-global-regions/, archived at http://archive.ph/2fowo/image

COMCEC. (2015). Effective Tourism Marketing Strategies: ICT-Based Solutions for the OIC Member Countries. Ankara, Turkey: COMCEC Coordination Office.

Daries, N., Cristobal-Fransi, E., Ferrer-Rosell, B., \& Marine-Roig, E. (2018). Maturity and development of highquality restaurant websites: A comparison of Michelin-starred restaurants in France, Italy and Spain. International Journal of Hospitality Management, 73, 125-137. doi:https://doi.org/10.1016/j.ijhm.2018.02.007

de Rosa, A. S., Bocci, E., \& Dryjanska, L. (2019). Social representations of the European capitals and destination ebranding via multi-channel web communication. Journal of Destination Marketing and Management, 11, 150165. doi:https://doi.org/10.1016/j.jdmm.2017.05.004

Doolin, B., Burgess, L., \& Cooper, J. (2002). Evaluating the use of the Web for tourism marketing: a case study from New Zealand. Tourism Management, 23(5), 557-561. doi:http://dx.doi.org/10.1016/So261-5177(o2)ooo14-6

Douglas, A., Lubbe, B., \& van Rooyen, A. (2018). Business travellers' use of mobile travel applications: a generational analysis. Information Technology E Tourism, 18(1), 113-132. doi:https://doi.org/10.1007/s40558017-0103-6

Fernández-Cavia, J., Rovira, C., Díaz-Luque, P., \& Cavaller, V. (2014). Web Quality Index (WQI) for official tourist destination websites. Proposal for an assessment system. Tourism Management Perspectives, 9, 5-13. doi:https://doi.org/10.1016/j.tmp.2013.10.003

Foris, D., Tecau, A. S., Hartescu, M., \& Foris, T. (2019). Relevance of the features regarding the performance of booking websites. Tourism Economics, 2019. doi:https://doi.org/10.1177/1354816619845790

Gibbs, C., Gretzel, U., \& Saltzman, J. (2016). An experience-based taxonomy of branded hotel mobile application features. Information Technology \& Tourism, 16(2), 175-199. doi:https://doi.org/10.1007/s40558-016-0052-5

Google. (2014). Principles of mobile site design: delight users and drive conversions. Retrieved from https://www.thinkwithgoogle.com/_qs/documents/538/multi-screen-moblie-whitepaper_researchstudies.pdf

Google. (2019). Prepare for mobile-first indexing. Retrieved from https://developers.google.com/search/mobilesites/mobile-first-indexing, archived at http://archive.ph/xLomp/image 
Groth, A., \& Haslwanter, D. (2016). Efficiency, effectiveness, and satisfaction of responsive mobile tourism websites: a mobile usability study. Information Technology $\mathcal{E}$ Tourism, 16(2), $201-228$. doi:https://doi.org/10.1007/s40558-015-0041-o

Inostroza, R., Rusu, C., Roncagliolo, S., Jimenez, C., \& Rusu, V. (2012, 16-18 April 2012). Usability Heuristics for Touchscreen-based Mobile Devices. Paper presented at the 2012 Ninth International Conference on Information Technology - New Generations.

Jiménez-Barreto, J., \& Campo-Martínez, S. (2018). Destination website quality, users' attitudes and the willingness to participate in online co-creation experiences. European Journal of Management and Business Economics, 27(1), 26-41. doi:https://doi.org/10.1108/EJMBE-11-2017-0048

Kamboj, S., \& Gupta, S. (2020). Use of smart phone apps in co-creative hotel service innovation: an evidence from India. Current Issues in Tourism, 23(3), 323-344. doi:https://dx.doi.org/10.1080/13683500.2018.1513459

Kelling, C., Väätäjä, H., \& Kauhanen, O. (2017). Impact of device, context of use, and content on viewing experience of 36o-degree tourism video. Paper presented at the Proceedings of the 16th International Conference on Mobile and Ubiquitous Multimedia, Stuttgart, Germany, November 26-29, 2017.

Kolawole, I. O. (2019). Validating Scales for Tourism Impacts, Quality of Life, and Support Tourism: An Exploratory Factor Approach (Vol. 10).

Lalicic, L., \& Weismayer, C. (2016). The passionate use of mobiles phones among tourists. Information Technology $\mathcal{E}$ Tourism, 16(2), 153-173. doi:https://doi.org/10.1007/s40558-015-0042-z

Lalicic, L., \& Weismayer, C. (2018). Being passionate about the mobile while travelling. Current Issues in Tourism, 21(8), 950-963. doi:https://doi.org/10.108o/13683500.2016.1141179

Law, R., Qi, S., \& Buhalis, D. (2010). Progress in tourism management: A review of website evaluation in tourism research. Tourism Management, 31(3), 297-313. doi:https://doi.org/10.1016/j.tourman.2009.11.007

Lebe, S. S. (2006). European spa world: Chances for the project's sustainability through application of knowledge management. Journal of Quality Assurance in Hospitality E Tourism, 7(1-2), 137-146.

Leung, D., \& Dickinger, A. (2019). How friendly destination websites are for mobiles? A study of destination marketing organizations in the Asia Pacific region. Asia Pacific Journal of Tourism Research, 24(12), 1126-1140. doi:https://doi.org/10.1080/10941665.2019.1665560

Luna-Nevarez, C., \& Hyman, M. R. (2012). Common practices in destination website design. Journal of Destination Marketing and Management, 1(1-2), 94-106. doi:https://doi.org/10.1016/j.jdmm.2012.08.002

Mak, A. H. N., Wong, K. K. F., \& Chang, R. C. Y. (2009). Health or self-indulgence? The motivations and characteristics of spa-goers. International Journal of Tourism Research, 11(2), $185-199$. doi:https://doi.org/10.1002/jtr.703

Mandal, S., Roy, S., \& Raju, A. G. (2017). Exploring the role of website attractiveness in travel and tourism: empirical evidence from the tourism industry in India. Tourism Planning and Development, 14(1), 110-134. doi:https://doi.org/10.108o/21568316.2016.1192058

Martínez-Sala, A. M., Monserrat-Gauchi, J., \& Alemany-Martínez, D. (2020). User Usable Experience: A threedimensional approach on usability in tourism websites and a model for its evaluation. Tourism Management Perspectives, 33. doi:https://doi.org/10.1016/j.tmp.2019.100579

Marvel, M. (2002). Spa tourism in Central \& Eastern Europe. Travel E Tourism Analyst(6), v.1-v.37.

Morais, E. P., Cunha, C. R., \& Gomes, J. P. (2019). Comparison of Portugal and Spain tourism websites. Paper presented at the Proceedings of the 33rd International Business Information Management Association Conference, IBIMA 2019: Education Excellence and Innovation Management through Vision 2020.

Morrison, A. M., Taylor, J. S., \& Douglas, A. (2004). Website evaluation in tourism and hospitality: The art is not yet stated. Journal of Travel \& Tourism Marketing, 17(2-3), 233-251.

Nielsen, J., \& Molich, R. (1990). Heuristic evaluation of user interfaces. Paper presented at the Proceedings of the SIGCHI conference on Human factors in computing systems.

Pavlic, I., \& Portolan, A. (2012). Competitive Position of Croatia at The Mediterranean Tourism Market. Mediterranean Journal of Social Sciences, 3(6), 263.

Pencarelli, T. (2019). The digital revolution in the travel and tourism industry. Information Technology $\mathcal{E}$ Tourism, 2019. doi: https://doi.org/10.1007/s40558-019-0016o-3

Poon, A. (2003). Competitive strategies for a 'new tourism'. In C. Cooper (Ed.), Classic reviews in tourism (pp. 13o142). Clevendon, USA: Channel View Publications.

Reino, S., \& Hay, B. (2016). The use of YouTube as a tourism marketing tool. Paper presented at the 42nd Annual Travel \& Tourism Research Association Conference, Vail, CO, USA, June 14-16, 2016.

Ribeiro, F. R., Silva, A., Barbosa, F., Silva, A. P., \& Metrôlho, J. C. (2018). Mobile applications for accessible tourism: overview, challenges and a proposed platform. Information Technology \& Tourism, 19(1), $29-59$. doi:https://doi.org/10.1007/s40558-018-0110-2 
Rodríguez-Torrico, P., Prodanova, J., San-Martín, S., \& Jimenez, N. (2019). The ideal companion: the role of mobile phone attachment in travel purchase intention. Current Issues in Tourism, $2019,1-14$. doi:https://dx.doi.org/10.108o/13683500.2019.1637828

Snoj, B., \& Mumel, D. (2002). The measurement of perceived differences in service quality-The case of health spas in Slovenia. Journal of Vacation Marketing, 8(4), 362-379.

Stienmetz, J. L., Levy, S. E., \& Boo, S. (2013). Factors influencing the usability of mobile destination management organization websites. Journal of Travel Research, 52(4), 453-464.

Tarantino, E., De Falco, I., \& Scafuri, U. (2019). A mobile personalized tourist guide and its user evaluation. Information Technology E Tourism, 21(3), 413-455. doi:https://doi.org/10.1007/s40558-019-00150-5

Turnšek, M., \& Janecek, P. (2019). America first, the Netherlands second" on youTube: "spoofing" destination marketing with political satire. European Journal of Humour Research, 7(3), 26-45. doi:https://doi.org/10.7592/EJHR2019-7.3.janecek

WTO. (1999). Marketing Tourism Destinations Online: Strategies for the Information Age, . Madrid, Spain: World Tourism Organization Business Council.

Xiao, Y., Tao, Y., \& Li, Q. (2008). Web page adaptation for mobile device. Paper presented at the 2008 th International Conference on Wireless Communications, Networking and Mobile Computing (WiCOM), Dalian, China, 12 - 17 October 2008.

Yáñez Gómez, R., Cascado Caballero, D., \& Sevillano, J.-L. (2014). Heuristic Evaluation on Mobile Interfaces: A New Checklist. The Scientific World Journal, 2014(Article ID 434326). doi:https://doi.org/10.1155/2014/434326

Yeung, T. A., \& Law, R. (2004). Extending the modified heuristic usability evaluation technique to chain and independent hotel websites. International Journal of Hospitality Management, 23(3), $307-313$. doi:https://doi.org/10.1016/j.ijhm.2003.03.001

Zhang, D. (2007). Web content adaptation for mobile handheld devices. Communications of the ACM, 50(2), 7579. 